\title{
Standardization in Construction Environment: Adopting Standard Method of Measurements
}

\author{
Anis Rosniza Nizam Akbar, Mohamamd Fadhil Mohammad, \\ Norizan Ahmad, Myasarah Maisyam
}

Construction Economics and Procurement Research Group, Centre of Studies for Quantity Surveying, Faculty of Architecture, Planning \& Surveying, Universiti Teknologi MARA, 40450 Shah Alam, Selangor, Malaysia

anis.rosniza@gmail.com

\begin{abstract}
This paper prepared to investigate the current industry issues which are currently surrounding the application of current Malaysian Standard Method of Measurement (SMM) as a single standard system of measurement. An exploratory semi structured interview approach was conducted among the selected end-users. There are few important key points highlighted by the industry, which can be used as a guideline to be implemented in transforming the current Malaysian SMMs. The outcome of this paper expected to be used as a supporting data to be carried along to the next level of the main research, which aims to develop a more accepted and practical SMM for construction works in Malaysia.

Keywords: Standardization; bill of quantities $(\mathrm{BQ})$; contract document; standard method of measurement (SMM)

eISSN 2398-4295 @ 2018. The Authors. Published for AMER ABRA cE-Bs by e-International Publishing House, Ltd., UK. This is an open-access article under the CC BY-NC-ND license (http://creativecommons.org/licenses/bync-nd/4.0/). Peer-review under responsibility of AMER (Association of Malaysian Environment-Behaviour Researchers), ABRA (Association of Behavioural Researchers on Asians) and $c E-B s$ (Centre for EnvironmentBehaviour Studies), Faculty of Architecture, Planning \& Surveying, Universiti Teknologi MARA, Malaysia.

DOI: http://dx.doi.org/10.21834/ajbes.v3i12.131
\end{abstract}




\subsection{Introduction}

Construction industry is one of the important sectors that contribute to the growth of economic sector in Malaysia. In order to ensure the industry's growth, by having a good long term, rational and cost effective project or building, there is an urgent need within the industry to adopt standardization in construction information and documentation (Bandi \& Abdullah, 2012a; Perumal \& Abu Bakar, 2011). According to K. Abd Rashid (2002), Adnan et al. (2011) and Myles (2006) the nature and the environment of the construction industry were operated by separation and fragmentation of different organizations. Thus in order to minimize the impact of separation and fragmentation of varied key players in the construction industry, information was perceived as an enabler and an important input for coordination (Atkin, 1995; Griffith, Stephenson, \& Watson, 2000; Kwakye, 1997; McDonagh, 1995; Winch, 2010). Hence, instilling the awareness on the significance of adapting standardization in construction information as the assurance in increasing construction efficiency is required. Standardization will helps in achieving consistency in management and operations thus indirectly reduce the conflict among the key players. Smit \& Cronje (2002) stress out on the main purpose of adopting standardization is to develop a specific level of conformity.

The use of an appropriate standard BQ will allow consistent and better estimating, pricing bidding, cost control and records by players during the difference stages and process of building construction especially during the regeneration of urban infrastructure, dwellings and space in the construction environment which include civil engineering and building construction (R. Abd Rashid et al., 2006; Adnan et al., 2011; Peter R Davis et al., 2009). In order to come up with the appropriate $B Q$, the SMM used in the construction industry needs to be given proper and thorough review to ensure they are keeping up with new developments in the construction environment which include technology, stakeholders and players as well as, new demand by clients and end-users. The reviews of the literatures have suggested that the Malaysian SMMs was flagged with issues which rendered it to be inappropriate in its content, format and approach, not fully utilize by the key players thus leading to unstandardized information in the $\mathrm{BQ}$.

Although there are empirical evidence from past researches justified the presence of the issues, however without any coordinated effort in drawing the desired solution, the issues remain daunting and continue to become an academic and industry-wide concern. The concern have prompted questions to asked on what are the current issues pertaining to the current Malaysian SMMs and why the issues still daunting in Malaysian construction industry. Following the questions, this paper prepared to investigate the current issues pertaining to the current Malaysian SMMs. The current situations identified would be assessed as one of the prerequisite steps in suggesting the desired solution in order to make an adjustment on the current SMM to the items and terminology to reflect the Malaysian construction practices. Indirectly assist to achieve consistency and standardization of information to be used by various players during the difference stages and process of building construction especially during the regeneration of urban infrastructure, dwellings and space in the construction environment which include civil engineering and building construction. The outcome of this paper is expected to be as a supporting and fundamental data, carried along to the next level of the main research which aims to develop a more accepted and practical SMM for 
construction works in Malaysia.

\subsection{Literature Review}

\subsection{Adapting standardization in construction environment}

Construction industry is a fragmented and dynamic sector with a project based nature and involvement of innumerable key players. There are occurrences of separation and fragmentation element in the construction environment (K. Abd Rashid, 2002; Adnan et al., 2011; Myles, 2006). In order to minimize the impact of separation and fragmentation elements among the varied key players and difference project lifecycle, information was perceived as an enabler and an important input for coordination (Atkin, 1995; Griffith et al., 2000; Kwakye, 1997; McDonagh, 1995; Winch, 2010). However, in order to achieve this, it is a must for the key players involved being supplied with the right and sufficient information that matches precisely with the need of others (Atkin, 1995; Hackeet, Robinson, \& Statham, 2006; Kwakye, 1997; Liang, 1976). In construction industry, information remains the major source of activity and considered as the essence of construction management $(R$. Abd Rashid et al., 2006; Adnan et al., 2011; P. R. Davis \& Baccarini, 2004; Peter R Davis et al., 2009; Jaggar, Ross, Love, \& Smith, 2001). Based on a review on the importance and significant of information in the construction industry, and above to increase the efficiency of construction, instilling the awareness on the significance of adapting standardization in construction information needed.

Standardization will help in achieving consistency in management and operations thus indirectly reduce the conflict among the key players. Smit \& Cronje (2002) stress out on the main purpose of adopting standardization is to develop a specific level of conformity. Standard project documentation and records will indirectly assist to establish a reference line and become communication tools among project's key players. In order to achieve this, it is prerequisite to standardize the documents in the most professional way and define the requirement to support and enhance the management function daily by delivering good information especially with the increasing complexity of buildings, legal, statutory and contractual requirements in Malaysian current construction industry (K. Abd Rashid, 2011; Adnan et al., 2011; Razali \& Abd Rashid, 2011). In relations to this statement, by having good document standardization, internal communication between the various levels will indirectly be effective. According to Perumal \& Abu Bakar (2011) standardization contributes to increased productivity. This is due to the nature of the documents and information from one project to the next are being standardized at each stage of the construction process whereby it will create less confusion in the later stage.

In this line, $\mathrm{BQ}$ is a form of technical information generated in addition to numerous other forms of information created throughout the life of a construction project (Kwakye, 1997). BQ is a document containing a detailed list of works and the quantities required for a building or other civil engineering project used during pre and post contract stages. In other words, $B Q$ are used by the clients as a communication medium among the key players involved. $B Q$ is an important form of information, used at difference stage of project lifecycle, by providing 
necessary information to the construction key players (K. Abd Rashid, 2002; R. Abd Rashid et al., 2006; Adnan et al., 2011; Ashworth \& Hogg, 2002). Table 1 show the list of primary function of $B Q$ formulated from the literature done.

Table 1: List of primary function of $B Q$

\begin{tabular}{|l|}
\hline Pre Tender \& Tendering Stage \\
\hline b. Assist contractor with the preparation of an estimate for tendering \& providing useful information \\
Post Tendering Stage \\
a. Aid in the aspects of contract administration \& management \\
b. Having a proper monitoring and controlling of the construction process \\
c. Acts as construction management information; planning, programming, budgetary control, financial \\
reporting \& etc \\
d. Act as a legal document when implemented
\end{tabular}

(Source: Adnan et al., 2011; Bandi \& Abdullah, 2012b; Mohammad, 2012)

Based on table 1, it is clearly shown $B Q$ has been recognized as an important component in the overall process of construction (pre and post contract stage). It was mainly triggered by the extensive domination of the traditional lump sum system of construction procurement which essentially placed the $B Q$ as a primary element in its process (K. Abd Rashid, 2011; R. Abd Rashid et al., 2006; Adnan et al., 2011). Data from the Construction Industry Development Board (CIDB) quarterly construction statistical bulletin (2009-2012) as shown in Table 2 indicates the trend towards the traditional lump sum system of construction procurement carries on to remain strong years by years. Therefore, the statements plus the data had reaffirmed the representativeness of the BQ in Malaysian Construction Industry.

Table 2: The frequencies on the use of the traditional lump sum system as compared to other types of procurement (2007-2012)

\begin{tabular}{|l|c|c|c|c|c|c|c|c|c|c|c|c|}
\hline \multirow{2}{*}{$\begin{array}{l}\text { Types of } \\
\text { procurement }\end{array}$} & \multicolumn{2}{|c|}{2007} & \multicolumn{2}{|c|}{2008} & \multicolumn{2}{|c|}{2009} & \multicolumn{2}{|c|}{2010} & \multicolumn{2}{|c|}{2011} & \multicolumn{2}{|c|}{2012} \\
\cline { 2 - 12 } & No. & $\%$ & No. & $\%$ & No. & $\%$ & No. & $\%$ & No. & $\%$ & No. & $\%$ \\
\hline $\begin{array}{l}\text { Traditional } \\
\text { Lump Sum } \\
\text { system }\end{array}$ & 6906 & 93.86 & 6125 & 93.91 & 6724 & 95.52 & 6975 & 96.23 & 6867 & 96.53 & 1936 & 94.44 \\
\hline $\begin{array}{l}\text { Other types of } \\
\text { procurement }\end{array}$ & 452 & 6.14 & 397 & 6.09 & 315 & 4.48 & 273 & 3.77 & 247 & 3.47 & 114 & 5056 \\
\hline
\end{tabular}

(Source: Modified from CIDB quarterly construction statistical bulletin (Data as at June 2012) as cited by (Bandi \& Abdullah, 2012a) 
Although, in non-traditional procurement route process, design and construction are carried out parallel, the contractors still need to prepare a document as a basis for them to refer in paying their workers and claiming work done with their clients (R. Abd Rashid et al., 2006). In other word, both traditional and non-traditional procurement route need to depend on proper cost documentation for bidding, cost control and cost monitoring. Even though, $B Q$ being critic in which the preparation of $B Q$ is very complex and time consuming, it should be taken in a positive way and should be addressed professionally and scientifically since $B Q$ is useful to the clients and contractors in both procurement route (R. Abd Rashid et al., 2006; Adnan et al., 2011). Thus, It is prudent to review the primary functions and benefits of standard systems of measurement (on which BQs are based) to establish what potential utilizations there are for any construction work.

\subsection{The roles of SMM in standardized the $B Q$}

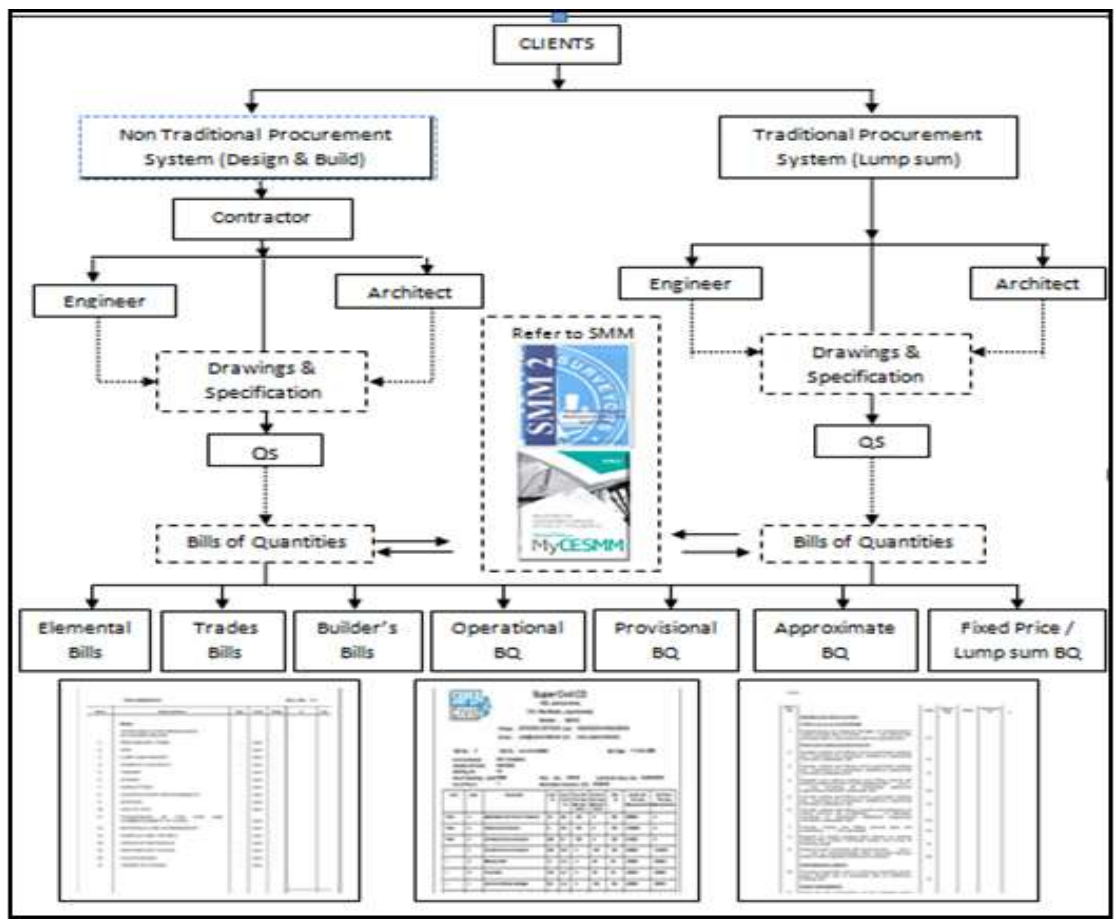

Figure 2: Significance and importance of SMM on the key player roles and activities that are involved in both traditional procurement and non-traditional procurement systems Title

In order to produce an appropriate $B Q$ which is properly measured, determined and quantified, a SMMs protocol has been developed and used (Mohammad, 2012). The SMM 
for building works (SMM2) and Malaysian Civil Engineering SMM (MyCESMM) are amongst the current standardized references used in Malaysia. In order to clarify the readers on the relationship between SMM and BQ, Figure 2 illustrates the relationships. It shows the SMMs are used by the Quantity Surveyors (QS) to standardize the method of preparing the measurement for building and Civil engineering work in producing procurement document or contract document which usually include the preparation of the BQ.

A comprehensive examination on the function of the SMM indicate that the rules of measurement drafted in SMMs are used for the purpose of producing a good standard procurement document (BQ) by obtaining a tender price for the project, and producing cost estimates or cost plans. Measurement is deemed to be strategically important to have an effective cost management of the construction project and the quality of measurement is dependent on the quantity and quality of design information, economic conditions plus the clarity of the available information (Yusuf \& Mohamad, 2012).

Figure 3 illustrate the level of accuracy that could be achieved using the available information listed (Oforeh, 2008; Potts, 1995). It shows how crucial it be to adopt SMM in preparing detail $B Q$ to achieve high accuracy in cost and contract management.

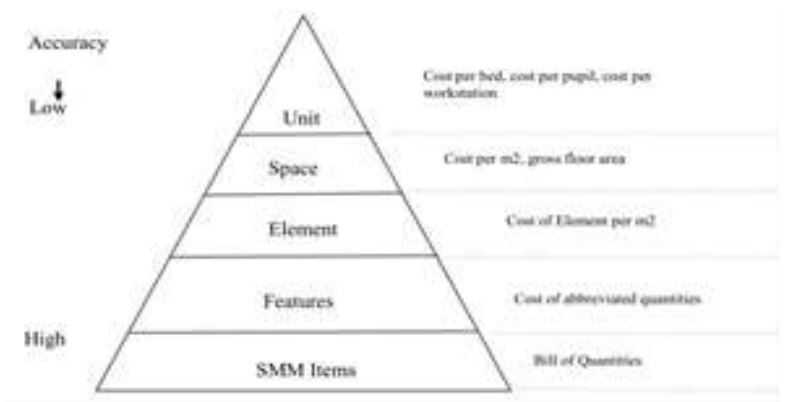

Figure 3: Level of accuracy that could be achieved using the available information

(Source: Oforeh, 2008; Potts, 1995)

\subsection{Issues in adopting SMM in construction industry}

SMMs are not without their critics (G. Nani et al., 2008; R. Abd Rashid et al., 2006; Adnan et al., 2011;Peter R Davis et al., 2009; J. B. Molloy, 2001; J. Molloy, 2007). Criticism and perspective on this issue have been discussed and deliberated quite lengthy by players and clients alike in publications as well as during conferences and seminars. Based on the literature conducted, several key issues or problems have been identified shown in Table 3 .

Table 3: List of issues which are currently surrounding the application of SMM as a single standard system of measurement in preparing a $B Q$.

\begin{tabular}{|l|l|l|}
\hline \multicolumn{1}{|c|}{ Category } & \multicolumn{1}{|c|}{ Issues identified } & \multicolumn{1}{c|}{ Researchers } \\
\hline $\begin{array}{l}\text { Contents \& } \\
\text { approach }\end{array}$ & $\begin{array}{l}\text { Complication of the SMM } \\
\text { Measurement's content, description } \\
\text { and approach }\end{array}$ & $\begin{array}{l}\text { (P. R. Davis \& Baccarini, 2004; Peter R Davis } \\
\text { et al., 2009; Goh \& Chu, 2002; J. B. Molloy, } \\
\text { 2000) }\end{array}$ \\
\hline
\end{tabular}




\begin{tabular}{|c|c|c|}
\hline & $\begin{array}{l}\text { Unclear in describing the meaning } \\
\text { of the items and the rules of } \\
\text { measurement }\end{array}$ & $\begin{array}{l}\text { (Abdul Aziz \& Ali, 2004; Adnan et al., 2011; } \\
\text { Misnan, Mohd Yusof, \& Bakri, 2002) }\end{array}$ \\
\hline & $\begin{array}{l}\text { SMM rule promote inaccuracies in } \\
\text { description \& unit of measurement } \\
\text { thus leading to the difficulties for } \\
\text { the contractor to price }\end{array}$ & $\begin{array}{l}\text { (R. Abd Rashid et al., 2006; Adnan et al., 2011; } \\
\text { Kim, 1992; Misnan et al., 2002; Wood \& } \\
\text { Kenley, 2004) }\end{array}$ \\
\hline \multirow[t]{2}{*}{ Current Usage } & $\begin{array}{l}\text { Occurrence on the usage of various } \\
\text { types of Standard Method of } \\
\text { Measurement due to no regulation } \\
\text { and enforcement body }\end{array}$ & $\begin{array}{l}\text { (P. R. Davis \& Baccarini, 2004; Peter R Davis } \\
\text { et al., 2009) }\end{array}$ \\
\hline & $\begin{array}{l}\text { Consultant utilize their own in } \\
\text { house method of measurement } \\
\text { (MoM) and etc (measurement, } \\
\text { classification and description of } \\
\text { the same items in various ways) }\end{array}$ & ( J. B. Molloy, 2000; J. Molloy, 2007) \\
\hline \multirow[t]{2}{*}{$\begin{array}{l}\text { Current practice of } \\
\text { developing SMM }\end{array}$} & $\begin{array}{l}\text { Copy and reuse other countries } \\
\text { SMM without looking into it deeply } \\
\text { and relate it with our country's } \\
\text { needs and practice }\end{array}$ & (Utama et al., 2008) \\
\hline & $\begin{array}{l}\text { Inadequate industry consultation } \\
\text { during their development stage }\end{array}$ & (Goh \& Chu, 2002) \\
\hline \multirow[t]{3}{*}{$\begin{array}{l}\text { Unable to fulfill the } \\
\text { demand of } \\
\text { construction } \\
\text { environment }\end{array}$} & $\begin{array}{l}\text { Measurement and the presentation } \\
\text { should follow a set of standard } \\
\text { rules that are familiar to both } \\
\text { consultant and contractor. }\end{array}$ & (Adnan et al., 2011; Mohammad, 2012) \\
\hline & $\begin{array}{l}\text { Inability of the measured items to } \\
\text { adequately represent real costs; } \\
\text { measurement for pricing purposes, } \\
\text { variation etc. }\end{array}$ & $\begin{array}{l}\text { (R. Abd Rashid et al., 2006; Adnan et al., 2011; } \\
\text { Goh \& Chu, 2002; Misnan et al., 2002; } \\
\text { Morledge \& Stuart, 2005) }\end{array}$ \\
\hline & $\begin{array}{l}\text { Heavily biased towards tendering } \\
\text { rather than administrative cost } \\
\text { control purposes }\end{array}$ & $\begin{array}{l}\text { (Adnan et al., 2011; Kim, 1992; Misnan et al., } \\
\text { 2002; Mohammad, 2012; Morledge \& Stuart, } \\
\text { 2005; G. Nani et al., 2008) }\end{array}$ \\
\hline $\begin{array}{l}\text { Unimproved } \\
\text { format }\end{array}$ & $\begin{array}{l}\text { Updating and improving the current } \\
\text { Malaysian's SMM2 into tabulated } \\
\text { format would allow for easier } \\
\text { computerization \& incorporation } \\
\text { into QS software }\end{array}$ & (Smith, 2004) \\
\hline
\end{tabular}

Despite the significances and importance of the SMM as a referred document to produce standard $\mathrm{BQ}, \mathrm{SMM}$ is plagued with issues listed above. The concerns have provoked questions to be asked on why the issues are still daunting in Malaysian construction industry and how research effort could be channeled to address the concerns over the identified issues. Following the questions, a study has been conducted with an aim to explore the issues and problems pertaining to the current Malaysian SMMs. In order to achieve the aim outlined in this paper, two objectives were proposed: (1) Conducting a preliminary survey among the end users in order to reconfirm the issues identified and identify new issues on the application of the SMM in the Malaysian construction industry, and (2) 
synthesize the outcome of the survey, to use as a supporting and fundamental data to be carried along to the next level of the main research which aims to develop a more accepted and practical SMM for construction works.

\subsection{Methodology}

The study started with a review of relevant literature which includes various materials. Then an exploratory semi structured interview of the practitioners in the industry was conducted. The exploratory semi structured interview approach was used in order to confirm the issues identified through the literature done, obtained first-hand information and gained an initial understanding regarding problems identified. The professionals targeted are mainly QS who are working in clients, consultancy and contracting organization in order have an equal view from each main key players. A total of 25 face to face interviews was conducted among the selected key players which are selected through Construction Industry Development Board (CIDB) and Royal Institution of Surveyors Malaysia (RISM); Client (7), consultant (12) and contractors (6). They are selected based on their expert, experience and willingness to share their viewpoint on the issues of current Malaysian SMM. Firstly the respondents are personally contacted by phone to briefly explain on the purpose of the study and ask for their willingness to contribute their ideas and opinion on the issues. Then a set of questionnaire was presented to each interviewee by email before the interview for better understanding and communication during the interview session.

\subsection{Results and Discussion}

\subsection{Types of SMM used for both Building and Civil Engineering works}

Respondents were asked on the type of SMM they referred to in doing measurement works and preparing $B Q$ for both building and civil engineering works.

\section{4,1,1 Consultant Firm}

9 out of 12 QSs from consultant firm claimed they are referring to various types of SMM for building works. They are referring to either SMM1 or SMM2 when dealing with private projects. SMM 2 will be fully referred to when they are dealing with government projects. While for civil engineering works, they refer to CESMM3 (UK) and CESMM (Malaysia). They claim CESMM3 or others in house SMM will be referred when they are dealing with huge and complex civil engineering projects. Surprisingly, some of the respondents just refer to SMM2 or create their own SMM when preparing BQ for civil works. 7 out of 12 respondents claimed that they do not know the existence of the newly launched MyCESMM.

\subsubsection{Contractor Firm}

All of the respondents prefer to use SMM1 rather than SMM2 because of its categorization of work division are by trades. The result is in line with the findings in the secondary data 
reviewed during the first phase of this research which stated that current SMM are heavily biased towards tendering rather than administrative cost control purposes. For civil engineering works, they prefer to use CESMM3 that are based on the UK practice. They claimed that, although the contractors do not have a choice as well as the responsibility to use the SMM in creating a $B Q$, the understanding and applicability of the document is necessary to enable them to appreciate the document. The contractors need to understand the description as well as familiar with the quantities provided by QS through the taking off process using the SMM in order to have a realistic and profitable project. They also claimed SMM is considered to be good when it is able to produce a description that can be easily understood, easily priced and represents the work carried out on site

\subsubsection{Clients}

Respondents representing the client are from the government sector, thus the SMM2 is the main document referred to by their department for building works. Meanwhile for civil engineering work, some of the older projects are still using CESMM while MyCESMM has only been used for new projects that commenced in early January 2013.

\subsection{Why some practitioners still prefer to refer to various types of SMMs}

Respondents from the consultants \& contractors firms elaborated that one of the reasons why some practitioners still prefer to use various types of SMMs is that they are not govern by any regulation and enforcement body that instructed them to adopt and refer to a single standard document in doing measurement work and preparing BQ. This answer was supported by the respondents representing the clients. They indicated that SMM is not a mandatory document to follow but if there are problems or issues raised in the middle of the project, they will then refer to a SMM. As a consequence, the practitioner should be underpinned and regulated by a standard document that is recognized by all key players to avoid any dispute which creates strain relationship among the key players. According to the senior respondents, persistent use of SMM1 is due to the fact that most renowned quantity surveying firms in Malaysia today were established by principal partners who had their education in the 1970s and 1980s when SMM1 was used in training quantity surveyors. They also claimed that most of the senior practitioners are reluctant to change due to their slow learning curve because of their age. Besides that, as per claimed by most of the respondents, for a mega project or when the projects involved foreign parties as one of the project's stakeholder, they would then prefer to adopt other countries SMM such as the SMM from the UK. This was due to the characteristics of the UK's SMM which were succeeded in producing $\mathrm{BQ}$ that have more realistic relationship with both the methods of working and the cost of carrying out the work, easier to compile, more beneficial to the contractor, better reflection on the costs involved, serve other purposes more effectively such as cost control across the works program and management of contract.

\subsection{Problems or issues pertaining to the current Malaysia SMMs'}

Table 4 shows the summary of the problems or issues pertaining to the current Malaysia SMMs' obtained through opinion survey of the local QSs in Malaysia. Most of the problems 
and issues listed below are in line with the findings from the secondary data review done at the initial stage of this research (shown in Table 2). The issues highlighted in table 4 indicate on the issues why the others in house types of SMMs are still being used by the practitioners in producing $B Q$.

Table 4: Summary of the problems or issues pertaining to the current Malaysian SMMs'

\begin{tabular}{|ll|}
\hline Issues highlighted \\
\hline$\bullet$ & Complicated rules and description; confused the users \\
\hline$\bullet$ & Unclear in describing the meaning of the items and the rules of measurement \\
\hline- & $\begin{array}{l}\text { Some of the important measurement rules or items of work are not highlighted in the clause; intendant } \\
\text { to miss out the element, should be highlighted by creating their stand-alone clause }\end{array}$ \\
\hline$\bullet$ & Existing of jargon word/term; not user friendly to some of the non-technical person \\
\hline$\bullet$ & $\begin{array}{l}\text { Some elements fail to acknowledge builder's knowledge or input; measurements are not fix with the } \\
\text { nature of contractor costing. }\end{array}$ \\
\hline$\bullet$ & Heavily biased towards tendering rather than administrative cost control purposes; current SMM used \\
\hline$\bullet$ & elemental format instead of trade format \\
\hline$\bullet$ & Current practice of developing SMM; Inadequate industry consultation during their development stages \\
\hline
\end{tabular}

\subsection{Suggestions to respond to the problems or issues discussed}

All respondents agreed on the need for the key players in the Malaysian construction industry to be underpinned by a standard system of measurement for the measurement work and preparing a $\mathrm{BQ}$. One of the proposed solutions to overcome the issues and problems listed in Table 2 and Table 4 is by modifying and enhancing the current SMM to be more practical and accepted model. 19 out of 25 respondents agreed with this proposed solution, whereby there is a need to modify and enhanced the current SMM. Among the suggestions are:

- Creating a set of measurement protocol that is user friendly for both consultant and contractor.

- Include simplicity \& comprehensiveness in the rules \& descriptions of the items.

- Consider to create a more realistic relationship with the methods of working, the SMM and the cost of carrying out the work.

- $\quad$ Give more benefits and fairness to the contractor by providing better reflection on the costs involved and the methods of working.

- $\quad$ Try to fix both tendering and administrative cost control purposes.

- $\quad$ Need to have adequate industry consultation during the development of the new SMM framework.

- $\quad$ The contents of the SMM should be up to date to suit the demand \& complexity of the current and future projects i.e. green and renewable energy technology; 
Industrialized Building System (IBS) and Advanced Mechanical and Electrical works.

\subsection{Conclusions}

This paper is prepared to confirm the findings from the review of the literature against an exploratory interview to give an insight of the real current issues pertaining to the Malaysian SMMs before proceeding to plan the next course of actions. According to the findings of this paper, the current situations would be assessed as one of the prerequisite steps in suggesting the desired solution in order to make an adjustment on the current SMM to the items and terminology to reflect the Malaysian construction practices. The SMM used in the construction industry also needs to be given proper and through review and revise to ensure they are keeping up with new developments in the construction environment which include technology, stakeholders and players, as well as new demand by clients and end users. Adapting Standardization by applying SMM will support the usage of an appropriate standard $\mathrm{BQ}$. It then will allow a consistent and better estimating, pricing bidding, cost control and records by players during the difference stages and process of building construction especially during the regeneration of urban infrastructure, dwellings and space in the construction environment which include civil engineering and building construction.

\section{Acknowledgement}

The Author is appreciative of the expertise of the supervisory committee and to industry collaborators for their practical and applied evaluations. A remark of indebtedness is also owed to the Universiti Teknologi MARA (UiTM) for sponsoring this research under Research Acculturation Grant Scheme (RAGS) 2013.

\section{References}

Abd Rashid, K. (2002). Construction Procurement in Malaysia : Processes and Systems: Constraints and Strategies. Kuala Lumpur: Research Centre International Islamic University Malaysia.

Abd Rashid, K. (2011). In Need of Studies to Assess the Effectiveness of Bills of Quantities. In 10th Management in Construction Research (MiCRA) Conference 2011. Kuala Lumpur.

Abd Rashid, R., Mustapa, M., \& Abd Wahid, S. N. (2006). Bills Of Quantities - Are They usefull and Relevant Today? In International Conference on Construction Industry (pp. 1-10).

Abdul Aziz, A. R., \& Ali, N. (2004). Outsourcing and quality performance: Malaysia's public works department. Structural Survey, 22(1), 53-60. doi:10.1108/02630800410530927

Adnan, H., Mohd Nawawi, A. H., Mohd Akhir, S. M., Supardi, A., \& Chong, H. (2011). Bills of Quantities : Perspectives of Contractor in Malaysia. Australian Journal of Basic and Applied Sciences, 5(11), 863-873. Retrieved from on 13 Dec 2011 
Ashworth, A., \& Hogg, K. (2002). Willis's Practice \& Procedure for the Quantity Surveyor. (11th Editi.). UK: Blackwell Science.

Atkin, B. (1995). Information management of construction projects in M.B.P. Brandon (Ed.), Integrated construction information. $E \&$ FN Spon.

Bandi, S., \& Abdullah, F. (2012a). Exploring Issues on the Usage of the Bills of Quantities (BQ) and Identifiying Relevent Research Area. In Management in Construction Research Association Postgraduate Conference. Kuala Lumpur: UTM Razak School of Engineering and Advanced Technology.

Bandi, S., \& Abdullah, F. (2012b). Understanding the Challenges in Sustaining the Bills of Quantities in Malaysia. In 16th Pacific Association of Quantity Surveyors Congress (PAQS 2012). Bandar Seri Begawan Brunei.

Cho, J.-H., Cha, W.-C., Seo, H.-W., Tak, S.-W., Lee, J.-S., \& Chun, J.-Y. (2007). Pratical Standard Methods of Measurement Cost Estimating in the Design Stage. In Dankook University (pp. 95-101). Korea.

Davis, P. R., \& Baccarini, D. (2004). The Use of Bills of Quantities in Construction Projects - An Australian Survey. In Proceedings of COBRA 2004. www.rics.org/site/download_feed.aspx?fileID=2789\&fileExtension=PDF on 7 March 2012

Davis, Peter R, Love, P. E. D., \& Baccarini, D. (2009). Bills of Quantities : Nemesis or Nirvana ? Emerald Journal, 27(2), 99-108.Retrieved from www.emeraldinsight.com/journals.htm?articleid=1793657\&show=pdf on 7 March 2012

Fang, T. F. (2010). The Application of SMM2 by Medium Sized QS Firm. Unpublished Dissertation for Degree of Bachelor of Quantity Surveying. Universiti Teknologi Malaysia.

Goh, H. B., \& Chu, L. . (2002). Developing National Standards for the Classification of Construction Information in Singapore. InInternational Council for Research and Innovation in Building and Construction CIB w78 conference 2002 (pp. 12-14).

Griffith, A., Stephenson, P., \& Watson, P. (2000). Management system for construction. Essex: Pearson Education.

Guan, C. K. (2010). Perspective of SMM2 among Consultant Quantity Surveyors. Publish Dissertation for Degree of Bachelor of Quantity Surveying. Universiti Teknologi Malaysia. Retrieved from http://www.fab.utm.my/download/Thesis/ThesisUGBQS2010ChongKwongGuan.pdf on 7 April 2010

Hackeet, M., Robinson, G., \& Statham, G. (2006). The Aqua Group Guide to Procurement, Tendering and Contract Administration. Oxford, United Kingdom: Blackwell Publishing.

Jaggar, D., Ross, A., Love, P. E. D., \& Smith, S. (2001). Overcoming Information Opacity in Construction: A Commentary. Logistics Information Management, 14(5/6), 413-421. doi:10.1108/EUM0000000006253

Kim, C. E. (1992). Satu Kajian Kritical terhadap Masalah-masalah yang Timbul dalam Penggunaan Dokumen Senarai Bahan sebagai Asas Menghargakan Tender : Dari Perspektif Kontraktor. University Teknology Malaysia.

Kwakye, A. A. (1997). Construction Project Administration in Practice. Essex: Addison Wesley Longman Limited.

Liang, W. M. (1976). A New Approach to Construction Management through Building Measurement and Time Standards. Lancaster, England: The Construction Press Ltd.

McDonagh, N. H. (1995). Information systems research in construction - a foreword. In M. B. P. Brandon (Ed.), Integrated construction information. London: E \& FN Spon. 
Misnan, M. S., Mohd Yusof, Z., \& Bakri, A. (2002). Civil Engineering Standard Method of Measurement (CESMM) Aplikasi dalam Pengukuran Kerja Kejuruteraan Awam. In UTM conference (pp. 1-8). Retrieved from http://www.fab.utm.my/download/ConferenceSemiar/ICCI2006S4PP01.pdf on 13 August 2011

Mohammad, M. F. (2012). Standard Method of Measurement: A Review of Its Importance and Relevance in Quantity Surveying Practice. In International Seminar 2012: Responding to Global Challenges- The Need for Quantity Surveyor Professional Standard. Jakarta.

Molloy, J. (2007). Civil Engineering Measurement Claims in Hong Kong. Strategic Integration of Surveying Services. FIG Working Week 2007., (May), 13-17. Retrieved from www.fig.net/pub/fig2007/papers/ts_3g/ts03_02_molly_1664.pdf on 6 March 2012

Molloy, J. B. (2000). Civil Engineering Measurement Disputes. HKIS Newsletter 9(8) September 2000. Retrieved from www.hkis.org.hk on 7 April 2011

Molloy, J. B. (2001). Destroying the Purpose of Bills of Quantities. HKIS Newsletter 10(8) September 2001. Retrieved from www.hkis.org.hk on 7 April 2011

Morledge, R., \& Stuart, K. (2005). The Effectiveness of Current Pricing Documentation from the Perspective of the Contractor's Estimator. In CIB W92/T23/W107 International Symposium on Procurement. New York USA.

Myles, T. R. (2006). Bills of What?- The Origin of Bills of Quantities. Hanscomb/Means Reports. Retrieved from http://www.cigs.org/public.asp?WCE=C=47|K=107913 on 6 March 2012

Nani, G., Edwards, P. J., Adjei-Kumi, T., Badu, E., \& Amoah, P. (2008). Customisation and desirable characteristics of a standard method of measurement for building works in Ghana. The Australasian Journal of Construction Economics and Building, 8(2), 30-40. Retrieved from https://www.google.com.my/\#hl=en\&sugexp=les\%3B\&gs_rn=2\&gs_ri=hp\&tok=9UzsoAl4ySwykBDB1zUShg\&pq=t he australian standard method of measurement further problems\&cp=46\&gs_id=40q\&xhr=t\&q=the+australian+standard+method+of+measurement- APA style as submitted in full paper. 